\title{
Beneath the peat: A refined pollen record from an interstadial at Caledonia Fen, highland eastern Victoria, Australia
}

\section{A. Peter Kershaw}

School of Geography and Environmental Science, Monash University, Australia peter.kershaw@arts.monash.edu.au

\section{G. Merna McKenzie}

School of Geography and Environmental Science, Monash University, Australia

\section{Jonathan Brown}

School of Geography and Environmental Science, Monash University, Australia

\section{Richard G. Roberts}

GeoQuEST Research Centre, School of Earth and Environmental Sciences, University of Wollongong, Australia

\section{Sander van der Kaars}

School of Geography and Environmental Science, Monash University, Australia, and Department of Palynology and Climate Dynamics, Albrecht-von-Haller-Institute for Plant Sciences, University of Göttingen, Germany

\section{Introduction}

The reconstruction of past vegetation has traditionally been based on peat deposits because of their accessibility and abundance in previously glaciated landscapes of northwestern Europe where the interest originated, the fact that pollen analysis can be combined with identification of macrofossils and peat stratigraphy to maximise knowledge of past vegetation and its controls, particularly climate, and the ease with which sediment cores for analysis can be extracted. The interest was extended to the Australasian region largely by researchers from, or trained at, European institutions, especially the Godwin Institute 
for Quaternary Research (GIQR) at the University of Cambridge. Peat studies caught on well in New Zealand and have been practised for many years, originally by Lucy Cranwell and subsequently by Neville Moar, Matt McGlone and others. But the predominantly unglaciated and arid landscape of Australia did not initially seem to have great appeal or promise, although GIQR-trained David Churchill and Sue Duigan undertook initial pollen studies on peat deposits. There was general disappointment when Donald Walker, on his arrival at the Australian National University to establish a palynological laboratory, declared the general unsuitability of Australia for such research and commenced work on the peatlands of previously glaciated highland New Guinea.

As a student of Walker's, Geoff Hope was sent to New Guinea, where he developed a lifetime passion for peatland investigation in exotic places and, when geographically constrained, for investigation of the rare bogs of southeastern Australia. Hope's approach of accumulating sediments with a small peat sampler, often hidden away in 'tourist' baggage, or even borrowing a spade if no sampler was available (see Figure 1) may appear to be hit-and-run tactics, but the conservation value of these acquisitions has become progressively apparent as this natural archive has been increasingly destroyed by land-use activities, peatland and bushfires and, recently, greenhouse-induced climate change.

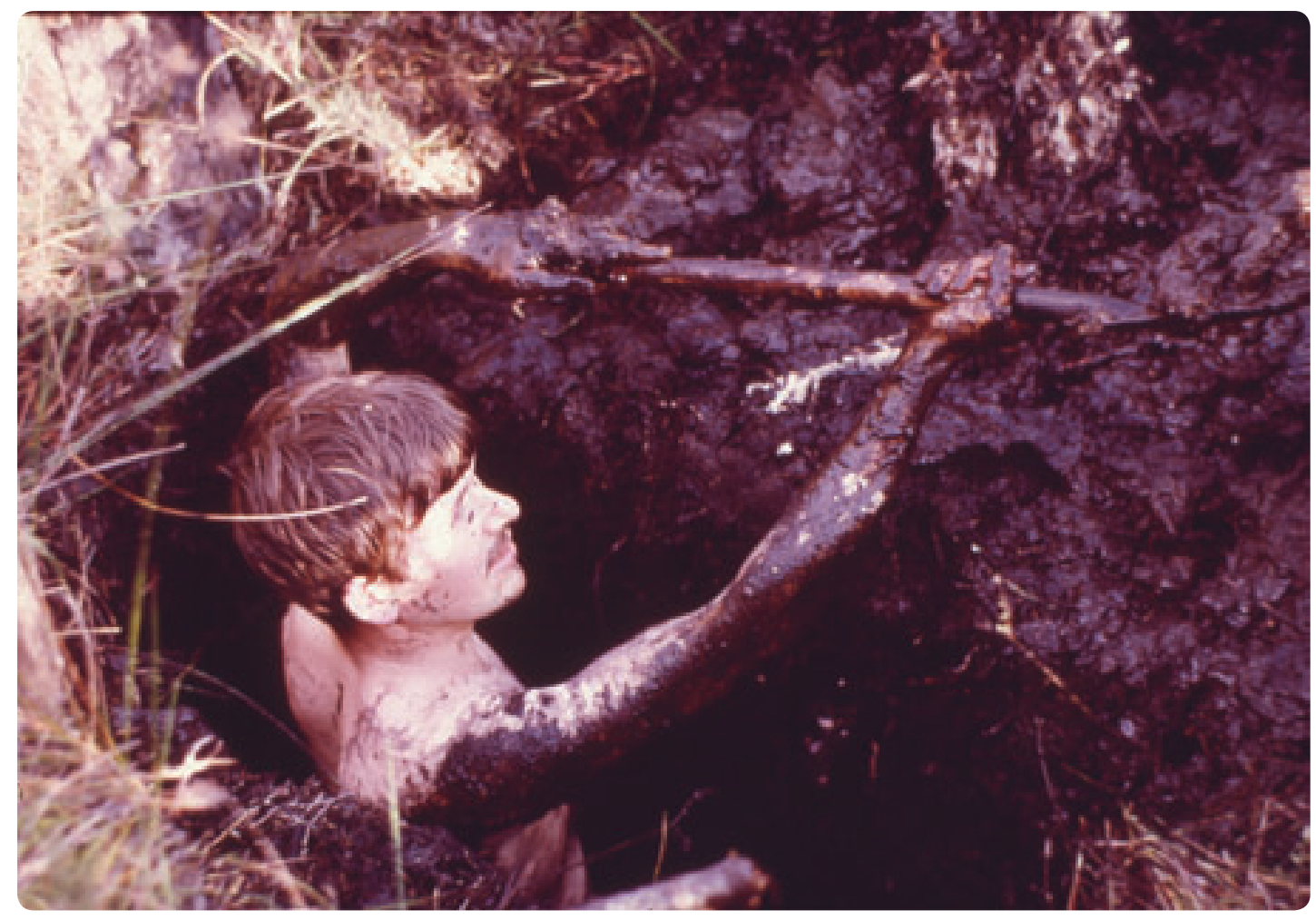

Figure 1. Geoff has always been into peat stratigraphy (from Hope 1968)

Although what was often a one-man operation can be sufficient to extract sediment accumulated since the last glacial period, especially in shallow glaciated depressions, it may fail to reveal any older material. The construction of substantially older records was traditionally considered of limited and dubious value because problems in dating and correlation often led to endless chronological and palaeoecological debate and speculation. However, improvements in the applicability of radiocarbon dating, the development of techniques capable of producing ages beyond those available from radiocarbon dating, and an increasing interest in preHolocene events that may have bearing on the understanding of the present landscape and prediction of future environmental change, has elevated the status of longer records. 
Caledonia Fen, a shallow peat deposit in the southeastern highlands of Victoria, after initially being dismissed as too condensed to provide a good Holocene record (Phil Ladd pers comm.), was later found, surprisingly, to extend into polleniferous 'glacial' sediments that could not be penetrated far with hand-operated corers, nor dated using available conventional radiocarbon methods. A pollen diagram was produced and published in summary form (Kershaw et al. 1983, 1991), before research was suspended for many years. The impetus for further study was provided by the interest of technicians Jack Misson and David Tooth in the development of appropriate coring devices, a passion for highland vegetation history and the persuasive powers of one of us (GMM), 'willing' student power, and the development of accelerator mass spectrometry (AMS) radiocarbon dating. The presence of a narrow band of organic sediment near the base of an $8 \mathrm{~m}$ core led to speculation that this represented climatic amelioration during the Last Interglacial - until a subsequent broader organic layer, that might be better related to the Last Interglacial, was recorded towards the base of an $18 \mathrm{~m}$ core. Pollen analysis seemed to demonstrate, from forest expansion, that there was a similar increase in temperature within both layers, generally equivalent to that of the Holocene. A combination of AMS radiocarbon ages on plant and insect macrofossils and optically stimulated luminescence (OSL) ages on quartz grains strongly suggested that the upper organic band occurred during the last glacial period and the lower layer most likely represented the Last Interglacial. Selected features of the full palynological record, analysed at the high resolution of one sample per 4 $\mathrm{cm}$, are shown in Figure 2.

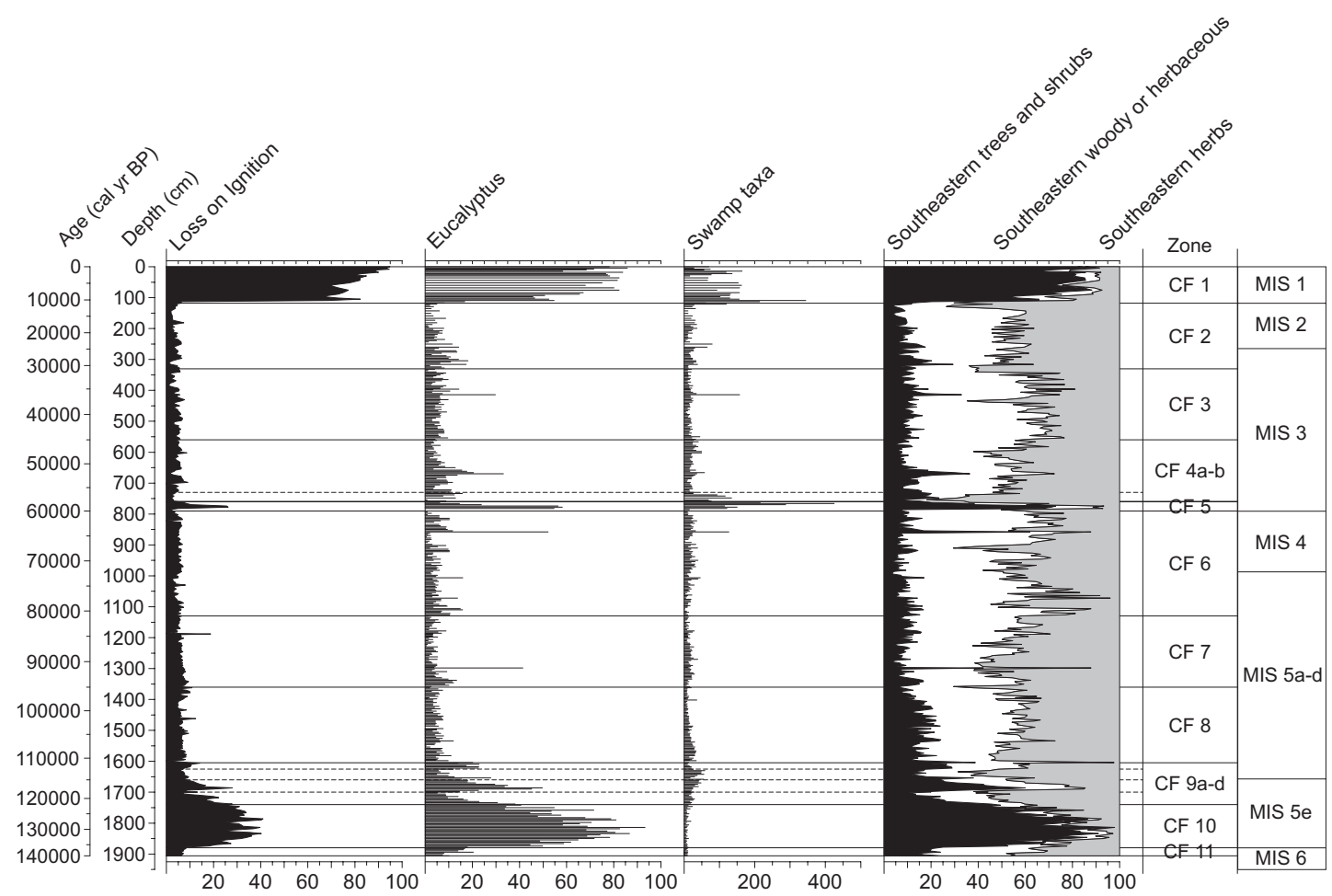

Figure 2. Selected features of the palynological record from Caledonia Fen (Kershaw et al. 2007) in relation to the Vostok ice-core chronology of Pettit et al. (1999)

This paper is focused on the age and duration of the upper organic layer and its significance for understanding the dynamics of high mountain vegetation and the nature and causes of glacial climate variation. The layer can be defined as an interstadial. This term was originally introduced to define a period of warming during a glacial period that was too short or of insufficient magnitude to lead to the full expansion of deciduous forest in northern Europe, as occurs during interglacials (West 1961). However, it has been applied to other areas where 
forest migration is not a problem and, as at Caledonia Fen, forest development occurred for only a short period. In some regions, especially those adjacent to, or greatly influenced by, the North Atlantic climate, phases of short-term forest development within the last glacial period have been linked to semi-regular Dansgaard-Oeschger (D-O) warming events, as defined in Greenland ice cores (Dansgaard et al. 1984), and currently termed Greenland Interstadials (GIs), with intervening cold phases termed Greenland Stadials (GSs) (Svensson et al. 2006). The vegetation response to D-O forcing appears to be variable within as well as between records (e.g. Sanchez Goñi et al. 2008), and it would be valuable to determine whether the single prominent interstadial at Caledonia Fen can be accommodated by any D-O GI, or whether there is any other explanatory mechanism.

For special investigation of this event, the sampling resolution, where material had not been completely lost during sediment removal for OSL dating, has been increased from every $4 \mathrm{~cm}$ to contiguous $1 \mathrm{~cm}$ intervals, while two additional OSL ages have been determined. These numerical ages provide the age model for the core section centred on the event. The section in question was extended temporally to allow examination of any short-term stadial variability and, in particular, to capture and examine the significance of occasional, single sample spikes in Eucalyptus pollen, sometimes accompanied by aquatic pollen peaks, in the glacial period (see Figure 2). Palynological analysis, sediment organic matter determination and OSL dating techniques follow those detailed in Kershaw et al. (2007).

\section{The site and its regional context}

Caledonia Fen $\left(37^{\circ} 20^{\prime} \mathrm{S}, 146^{\circ} 44^{\prime} \mathrm{E}\right)$ is a small depression, about $300 \mathrm{~m}$ by $160 \mathrm{~m}$, perched on a valley side at an altitude of $1280 \mathrm{~m}$ between the Caledonia River (c. $1150 \mathrm{~m}$ ) and the Snowy Range (c. $1650 \mathrm{~m}$ ) within the mountainous southeastern Australian Alpine National Park (Figure 3). The site was formed as part of a stream-eroded valley that was subsequently blocked off by mass-movement deposits and then infilled with fluviolacustrine and swamp sediments (Brown In prep.; Kershaw et al. 2007). Currently, the fen receives water from a number of small inlet streams and is drained by a single intermittent outlet stream. The basin is covered with a mix of bog and fen plant communities, most notably aquatic fen dominated by the emergent sedges Eleocharis sphacelata and Scirpus crassiusculus and submerged species Myriophyllum pedunculatum and M. propinquum (Haloragaceae), fen dominated by the sedge Carex gaudichaudiana and peat moss Sphagnum cristatum, and raised bog dominated by Sphagnum cristatum, the restiad Empodisma minus (Restionaceae), Carex gaudichaudiana and the heath Epacris paludosa. The most likely explanation for this vegetation mix is precipitation, as the current estimated $1530 \mathrm{~mm} /$ year (Houlder et al. 1999) is close to the threshold between dominance of wetter raised bog and drier fen within highland southeastern Australia (Kershaw et al. 2007).

The region experiences a temperate climate, with more than one-third of mean annual rainfall falling in the winter quarter (Bureau of Meteorology 1989). Although the westerly wind system brings moist and cloudy weather through much of the year, the region also experiences cold air masses emanating from the Southern Ocean close to Antarctica and also moist and warm tropical maritime air from the southern Pacific Ocean (Sturman and Tapper 2005). Mean annual temperature is estimated to be $7.3^{\circ} \mathrm{C}$, mean maximum temperature $19.1^{\circ} \mathrm{C}$, and mean minimum temperature $-1.2^{\circ} \mathrm{C}$. In cooler months, blizzard conditions may bring sub-zero maximum daily temperatures for several days at a time and frosts are common even in the warmest months. At altitudes above $1400 \mathrm{~m}$, winter precipitation is predominantly as snow, which accumulates from June until the spring thaw begins in September, providing the major source of water to Caledonia Fen. Generally speaking, 


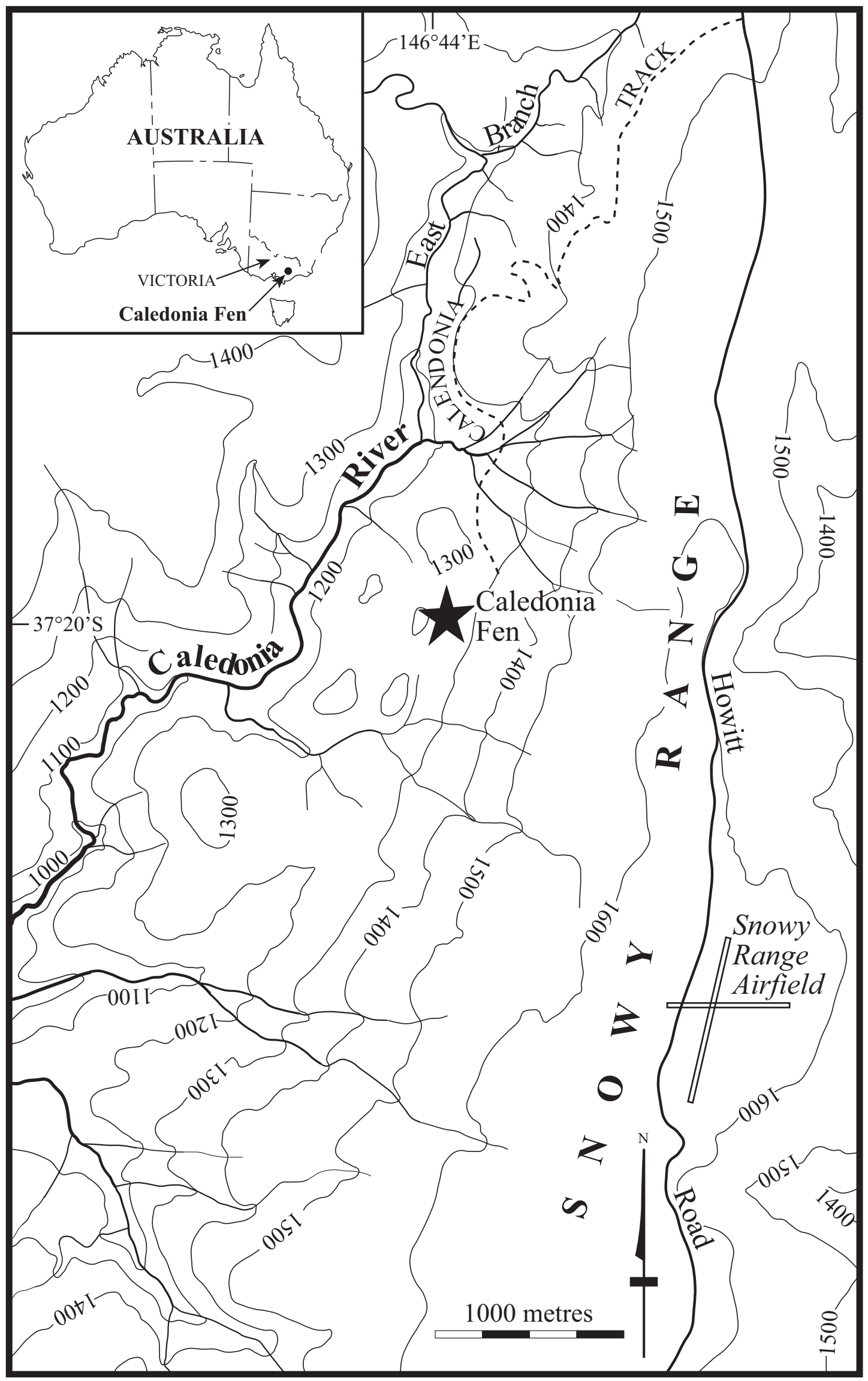

Figure 3. Location of Caledonia Fen. Based on the Tamboritha-Moroka 8223-S, 1:50,000 Topographic Map, Survey and Mapping Victoria, 1992 (modified from Kershaw et al. 2007) 
precipitation in the alpine and subalpine regions is often erratic and may lead to water stress in summer (Farrell and Ashton 1973).

Variations in regional vegetation can be broadly related to altitude (Figure 4). Caledonia Fen lies towards the upper limit of montane sclerophyll forest, dominated by Eucalyptus delegatensis on moister slopes and with a variety of other eucalypts, including E. dalrympleana and E. rubida, on drier and steeper aspects. These forests have an understorey composed of small trees, woody shrubs, herbs and ferns. They become more open with increased altitude and give way to sub-alpine woodland composed of E. pauciflora, E. stellulata and E. rubida, with the myrtaceous shrub Leptospermum grandifolium and a variable understorey of grasses, scattered shrubs and herbs around $1400 \mathrm{~m}$. A mosaic of treeless communities, including short and tall herbfield dominated by the Asteraceae, moist and wet heathland, grassland, bog and fen, occurs within sub-alpine woodland on the Snowy Range plateau, due to cold air drainage. Dry heathland, which forms a floristically and ecologically well-defined closed community, exists on rocky exposed ledges or steep gullies. It is characterised by the sole representative of the fire-sensitive, temperate rainforest conifers on mainland southeastern Australia, Podocarpus lawrencei (Podocarpaceae). The altitudinal treeline, estimated from that on Mount Kosciuzko to be around $1700 \mathrm{~m}$ (Figure 4), is not reached within the region.

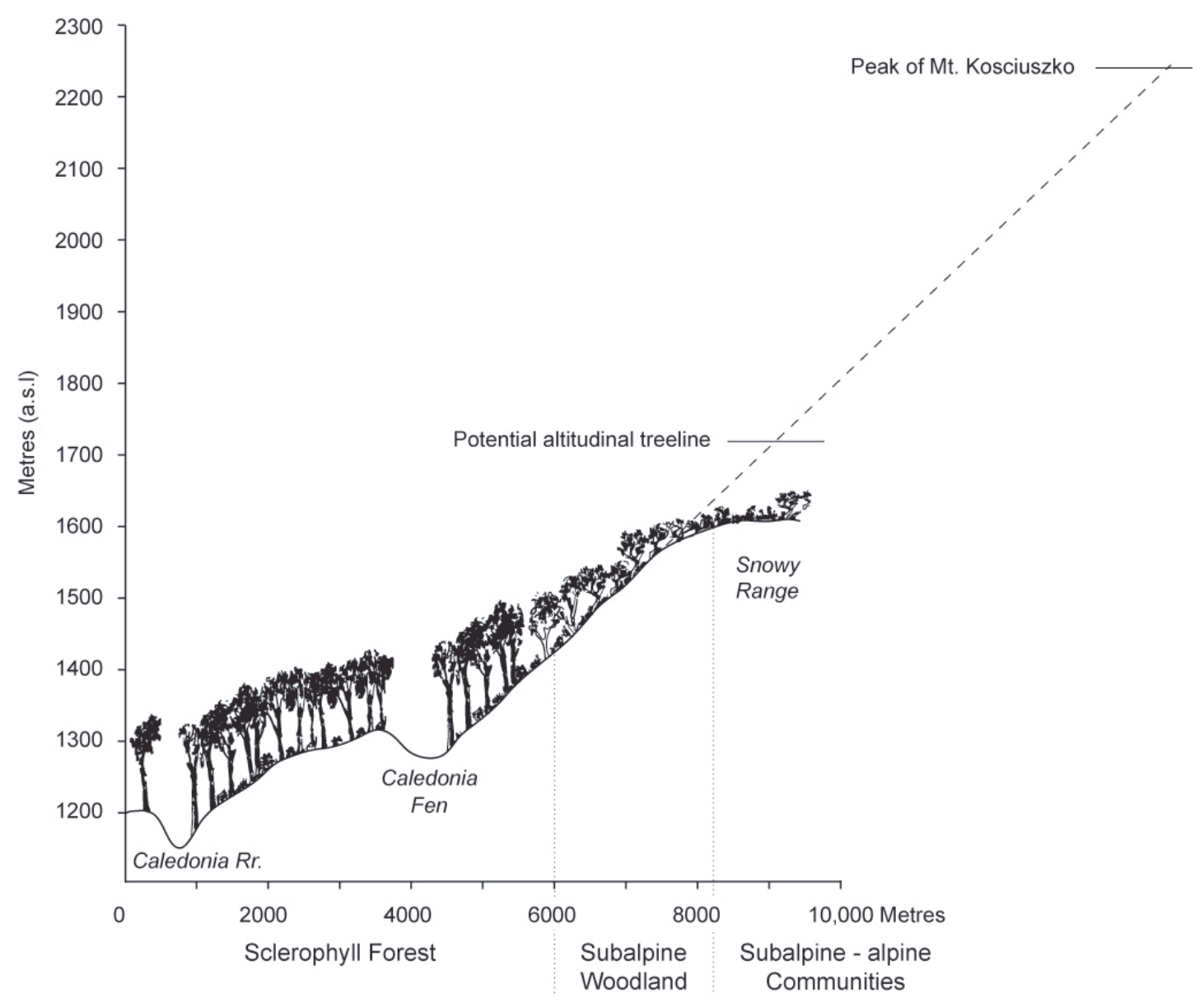

Figure 4. Vegetation transect from the Caledonia River to the Snowy Range in relation to the potential altitudinal vegetation zonation, including the estimated location of the tree line 


\section{Chronological considerations}

The chronology established for the whole core was based on its comparison with the Vostok temperature curve of Pettit et al. (1999), taking into account available AMS and OSL dates from the top $8 \mathrm{~m}$ of sediment. Actual ages were established for the zone and sub-zone boundaries, shown in Figure 2, and the age-depth curve is shown in Figure 5. For the section selected for study in this paper, it was considered appropriate to establish an independent timescale based on two original and two new OSL ages from within or bracketing the section (Figure 5), especially as the ages increase with depth (Table 1). The experimental uncertainties of several millennia associated with the ages mean that the inferred changes in sedimentation rate should be viewed with caution, but, overall, the ages probably provide a good indication of the length of time represented by the section. In relation to actual age, all dates are systematically older than predicted from correlation with the Vostok record and, although this may be the case, it could result from some incorrect assumptions about past changes in water content, as discussed in Kershaw et al. (2007). However, error bars just or nearly bisect the age-depth curve of the Vostok fitted chronology (Figure 5).

\section{Caledonia Fen}

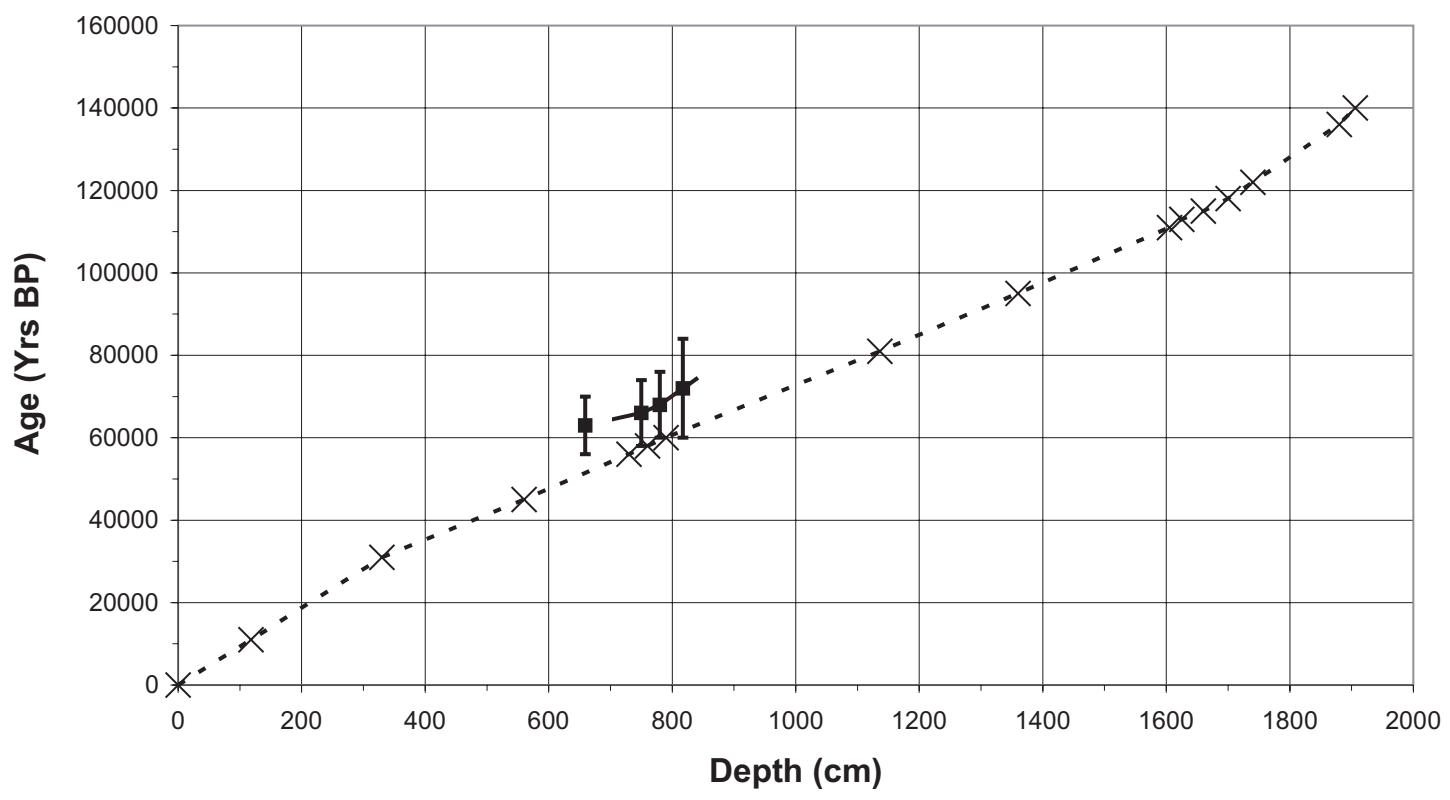

Figure 5. Age-depth curve for the Caledonia Fen record of Kershaw et al. (2007), determined from comparison of pollen zone and subzone boundaries (marked by Xs) with the Vostok ice-core chronology of Pettit et al. (1999). The offset curve (solid line) relates to the refined component of the record aged from the mean points of OSL age ranges within and bracketing this period. See Table 1 for details of OSL ages

\begin{tabular}{|l|l|l|l|}
\hline Sample code & Depth in core $(\mathrm{cm})$ & Optical age $(\mathrm{yr}$ BP) & Source \\
\hline CF9 & 659 & $63,000 \pm 7000$ & This paper \\
\hline CF4 & $748-755$ & $66,000 \pm 8000$ & Kershaw et al. 2007 \\
\hline CF3 & $776-783$ & $68,000 \pm 8000$ & Kershaw et al. 2007 \\
\hline CF10 & 817 & $72,000 \pm 12,000$ & This paper \\
\hline
\end{tabular}

Table 1. Luminescence results associated with the interstadial at Caledonia Fen 


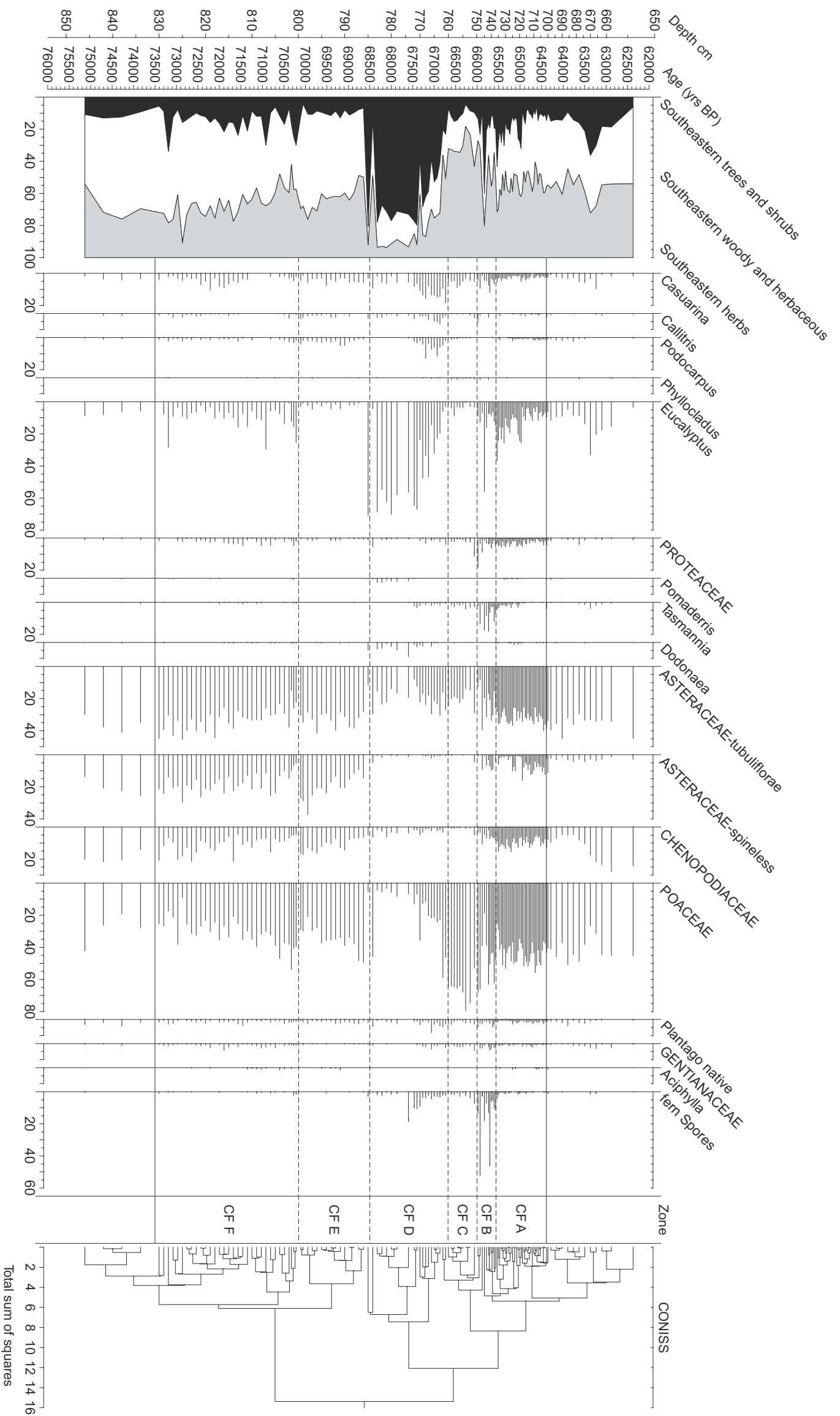

Figure 6. Selected dryland attributes of the refined component of the palynological record from Caledonia Fen embracing the major interstadial period. Taxon values are expressed as percentages of the dryland southeast Australian pollen sum (D'Costa and Kershaw 1997) for the appropriate sample 


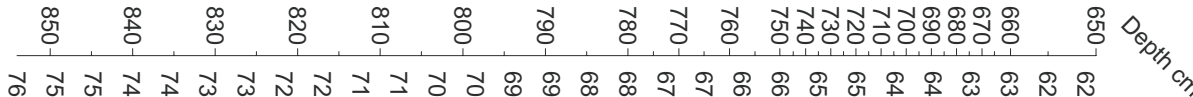

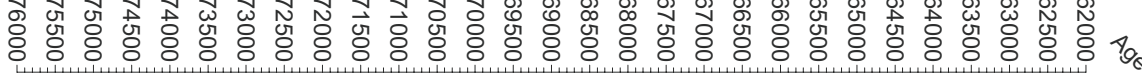
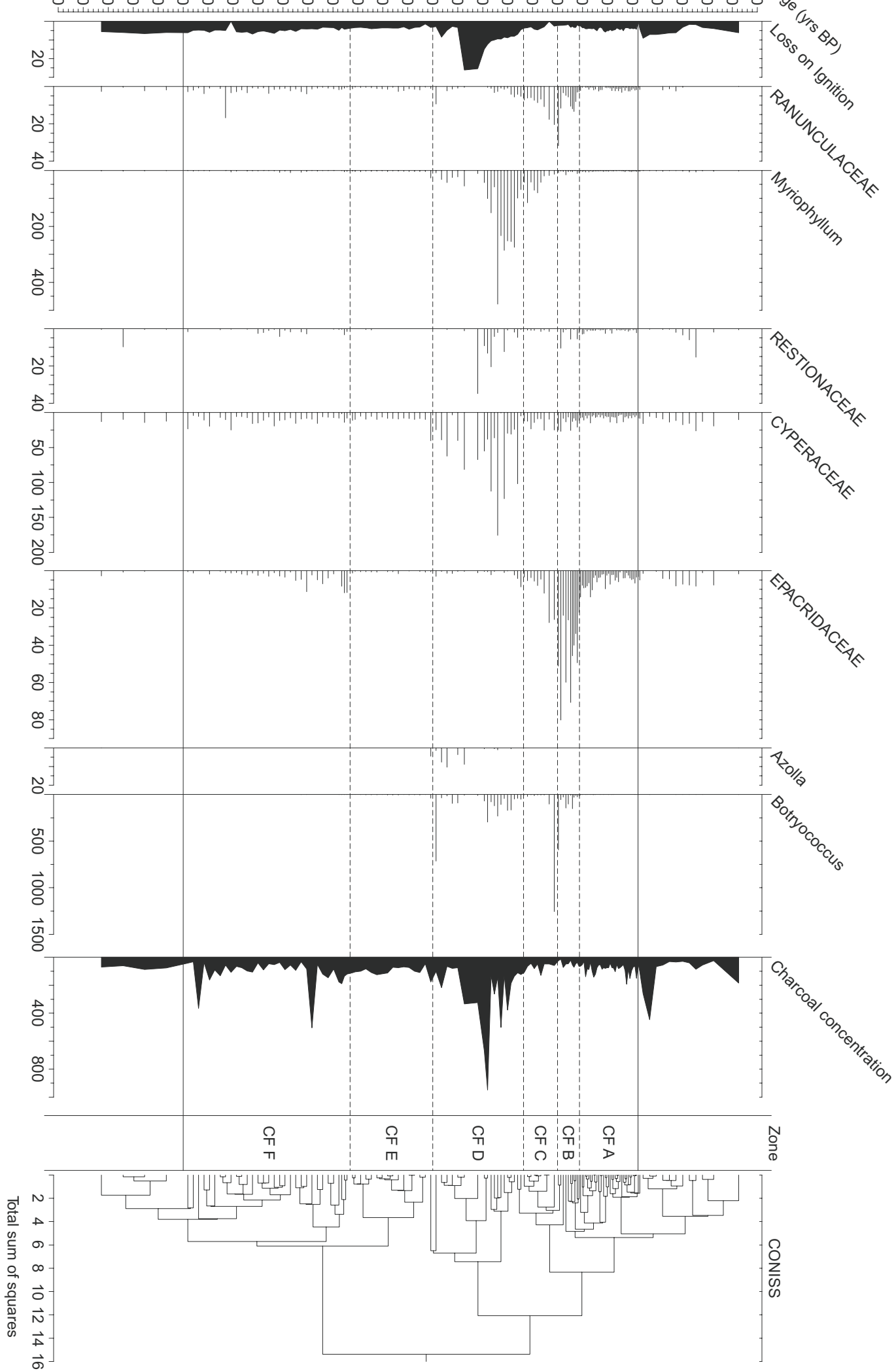

Figure 7. Selected aquatic attributes of the refined component of the palynological record from Caledonia Fen embracing the major interstadial period. Taxon values are expressed as percentages of the dryland southeast Australian pollen sum ( $D^{\prime}$ Costa and Kershaw 1997) for the appropriate sample 


\section{The palynological record}

Selected data are presented in Figures 6 and 7. They include major dryland (Figure 6) and aquatic taxa (Figure 7), all expressed as a percentage of the southeastern Australian pollen sum of regionally dispersed dryland taxa, which include the illustrated taxa Casuarina, Podocarpus, Phyllocladus, Eucalyptus, Pomaderris, Dodonaea, Asteraceae-tubuliflorae, Asteraceae-spineless, Poaceae and Plantago. Pollen sum taxa have been used also to construct the ratio diagram of trees and shrubs, woody and herbaceous taxa, and herbs. Also included are fern spore (predominantly tree fern) percentages in Figure 6, and charcoal concentration values in particles $/ \mathrm{cm}^{3}$, and loss on ignition (or organic content) values in Figure 7. The stratigraphically constrained classification, CONISS, based on pollen sum taxon values, has been employed to help determine a zonation scheme, although potentially slightly different response times to forcing influences at this resolution necessitate some flexibility in zone description. The refined component of the diagram extends from a depth of $830 \mathrm{~cm}$, with an estimated mean age of 73,400 years, to $700 \mathrm{~cm}$, with an estimated mean age of 64,300 years.

\section{Zone CFF (830-800 cm; c. 73,400-70,200 yr BP)}

High values for Poacaeae and Asteraceae pollen indicate the regional dominance of grassland and herbfield, while significant representation of Proteaceae, Gentianaceae and Aciphylla together indicate that these communities were alpine in character (McKenzie 1997; Martin 1999). High values of Chenopodiaceae suggest a drier facies of alpine vegetation than today, and vegetation that was probably steppic in character with no modern analogue (Martin 1999). Assuming the present-day lapse rate of $1.1^{\circ} \mathrm{C}$ lowering of temperature with every $100 \mathrm{~m}$ rise in altitude, mean annual temperatures would have been at least $4.5^{\circ} \mathrm{C}$ lower than today. Significant eucalypt pollen percentages could have been derived mainly from a much lower altitude treeline, but the likely absence of a marked treeline during the last glacial period, as indicated by lowland and other highland sites in the region (Kershaw 1998), suggests pollen transport to the site from distant to perhaps proximal forest, or woodland patches existing under locally moist and sheltered conditions. Consistently low loss-on-ignition values, combined with low values for aquatic taxa, suggest that the site was a low-productivity lake, probably because low temperatures resulted in ice cover for much of each year. However, fairly consistent or frequent representation of Ranunculus, Restionaceae, Cyperaceae and Epacridaceae may suggest that limited fen and bog vegetation grew on the site margin.

The zone shows significant variation in relative proportions of major dryland summary groups and, although this is perhaps exaggerated by the higher sample resolution than for the basal samples, it is notable in comparison with most other zones. It incorporates three sharp peaks in Eucalyptus pollen. Charcoal values are consistently low, apart from two sharp peaks that may indicate fires in the catchment.

\section{Zone CFE (800-785 cm; c. 70,200-68,600 yr BP)}

This zone is marked by overall lowest Eucalyptus percentages for the record, but generally higher values for other major woody taxa, Casuarinaceae, Callitris and Podocarpus. The consistency in percentages of Eucalyptus and Casuarinaceae strongly suggests regional to long-distance pollen dispersal, with the absence of a local source. As in the previous zone, the dominant woody or herbaceous taxa, Asteraceae and Chenopodiaceae, generally decrease through the zone relative to Poaceae. Aquatic taxon percentages are lowest for the record, suggesting minimal swamp representation in the basin. In fact, the extreme similarity in sample values for Cyperaceae is more consistent with a regional than proximal source. The overall impression from the pollen assemblages is that conditions were the most adverse for both woody and aquatic plants in 
the record. Background values for charcoal suggest also that the catchment vegetation did not carry fire.

\section{Zone CFD (785-764 cm; c. 68,600-66,800 yr BP)}

This zone is characterised by high values of tree pollen and reductions in Poaceae and the woody or herbaceous plants Asteraceae-spineless and Chenopodiaceae. Tree-pollen percentages are dominated by Eucalyptus, which rise sharply at the base, from less than 5\% to near 70\%, then plateau, before falling gradually but erratically to $20 \%$ at the top. The extent of expansion of forest, altitudinally as well as areally, is demonstrated by the near confinement of the pollen of lower-altitude wet and dry sclerophyll trees, Pomaderris and Dodonaea respectively, to this zone. The forest-pollen assemblage changes towards the top of the zone, as these taxa have reduced values, while Tasmannia and Podocarpus, as well as tree ferns, become prominent. Temperatures were clearly higher in the period represented by the zone as a whole and, from the overall assemblage composition, probably achieved levels similar to those of the Holocene. The changes towards the top of the zone suggest the temperature may have been lower to some degree and effective rainfall higher. The fact that there are also peaks for the diagram in Casuarina and Callitris within the upper part of the zone appears counter-intuitive, as they are best represented regionally under drier and warmer conditions. Either these trees were represented by taxa now absent from the region (that could include Cupressaceae pollen morphologically indistinguishable from Callitris and now confined to wetter highlands in Tasmania) or they indicate a high, long-distance component from greatly expanded lowland forests. Charcoal concentrations achieve much higher levels and are more frequent than elsewhere in the record, indicating a positive relationship between tree proximity and density and fire activity.

Within the basin, climatic amelioration clearly led to reduction in ice-cover duration, as aquatics were able to become well established. Cyperaceae has high values through the zone. Accompanying Azolla and Botryoccocus demonstrate the presence of open water in the early part of the zone. However, productivity within the lake, leading to significant organic matter accumulation, was delayed by about 500 years. The major peaks for the record in Myriophyllum and Restionaceae may indicate successional advancement, although the mix of open water to bog plants suggests a variable fen surface similar to that of today.

\section{Zone CFC (764-750 cm; c. 66,800-66,000 yr BP)}

This zone shows a major reversal from forest to open assemblages, similar to zone CFE except that Poaceae is dominant, Asteraceae-spineless is still largely absent and Chenopodiaceae is reduced to lowest percentages for the diagram. The achievement of highest values for Ranunculaceae and partially maintained percentages of Myriophyllum together suggest that temperatures were sufficiently high to maintain relatively ice-free conditions on site, while the ephemeral fen nature of this assemblage may explain, through oxidation, reduced organic content of the sediment. Drier conditions are also suggested by the near absence of bog Restionaceae, and possibly also by the absence of a clear charcoal peak, if this is interpreted as the inability of the vegetation to carry fire due to a sparse coverage. The postulation of a combination of dry and relatively warm conditions is difficult to reconcile with the low values of Eucalyptus and particularly Chenopodiaceae pollen. With Eucalyptus, it is possible perhaps that parent species in the area were not adapted to dryness or that they were poor pollen producers, as noted by Martin (1999) for Eucalyptus pauciflora, the present dominant of sub-alpine woodland. With Chenopodiaceae, it could have been that a change in the predominant wind direction or a substantial reduction in wind velocity had resulted in the loss of a long-distance component of salt-bush pollen from interior semi-arid shrublands. The nearest analogue in the extended 
Caledonia Fen record is a short Poaceae-dominated period that just precedes the Holocene (Figure 2), a time when temperatures were close to those of today (Williams et al. 2009).

\section{Zone CFB (750-735 cm; c. 66,000-65,500 yr BP)}

Shows sharp peaks in three major taxa (Asteraceae tubuliflorae, Poaceae and Eucalyptus) and consistently higher values of Asteraceae-spineless and Chenopodiaceae than in the previous zone. It is characterised as having highest values for Tasmannia, fern spores, and Epacridaceae for the diagram. The high values for Epacridaceae, together with relatively high percentages of Restionaceae, suggest the establishment of a bog within the basin, although high values for Botryococcus indicate the presence also of open water. The absence of Myriophyllum may relate to a higher level of acidity. Deposited sediments are surprisingly inorganic, suggesting that open water was not consistently present, a feature perhaps consistent with variable representation in dryland pollen components, or that oxidation of organics took place after deposition of these sediments. Although variable and apparently transitional in nature, conditions were sufficiently mild to allow survival of ferns and aquatic vegetation. The fact that Tasmannia is a frequent understorey taxon of, and palynologically can be indicative of, Eucalyptus pauciflora sub-alpine woodland (Martin 1999) may provide a more certain explanation for the relatively low eucalypt pollen values.

\section{Zone CFA (735-700 cm; c. 65,500-64,300 yr BP)}

Stadial conditions very similar to those of zone CFF are indicated, apart from generally lower values of Asteraceae-spineless - a feature of unknown significance due to the inability, thus far, to confidently identify source plants in the present landscape (Macphail and Martin 1991). In the lower part of the zone, even the variability in ratios of the summary dryland diagram are apparent, and there is an isolated peak in Eucalyptus towards the top of the zone.

\section{Discussion}

\section{The nature of the interstadial}

The interstadial is more extensive than originally envisaged, in that it began before the switch to a relatively high organic sediment component. It could be considered to embrace zone CFD, defined on continuous high values of Eucalyptus, which is estimated to have lasted about 1800 years. However, on proposed temperature grounds inferred largely from the representation of tree-fern spores and site evidence for colonisation by aquatic plants and some successional development within aquatic vegetation, it could have extended to the end of zone CFB, covering some 3000 years. In either case, the beginning is shown to be more abrupt than the ending. Regardless of definition, this period in the history of the fen is shown to be complex, with relatively frequent climate-driven changes.

\section{Affliation of the interstadial}

So-called interstadials during the last glacial cycle in the Australian region have generally been relatable to the orbital- and ice-forced periods MIS 5c, MIS 5a and early MIS 3 emanating from the North Atlantic region. However, the duration of the Caledonia Fen interstadial appears to be much shorter than these interstadials (that typically relate to semi-precessional cycles of about 10,000 years duration) and, therefore, the period is more likely to be driven or influenced also by a shorter-term millennial process. There are three major suggested causes of millennial-scale variability within the last glacial period: Dansgaard-Oeschger (DO) cycles, Antarctic climatic reversals, and high El Niňo-Southern Oscillation activity. All are suggested to have some expression in the few records from the Australian region that 


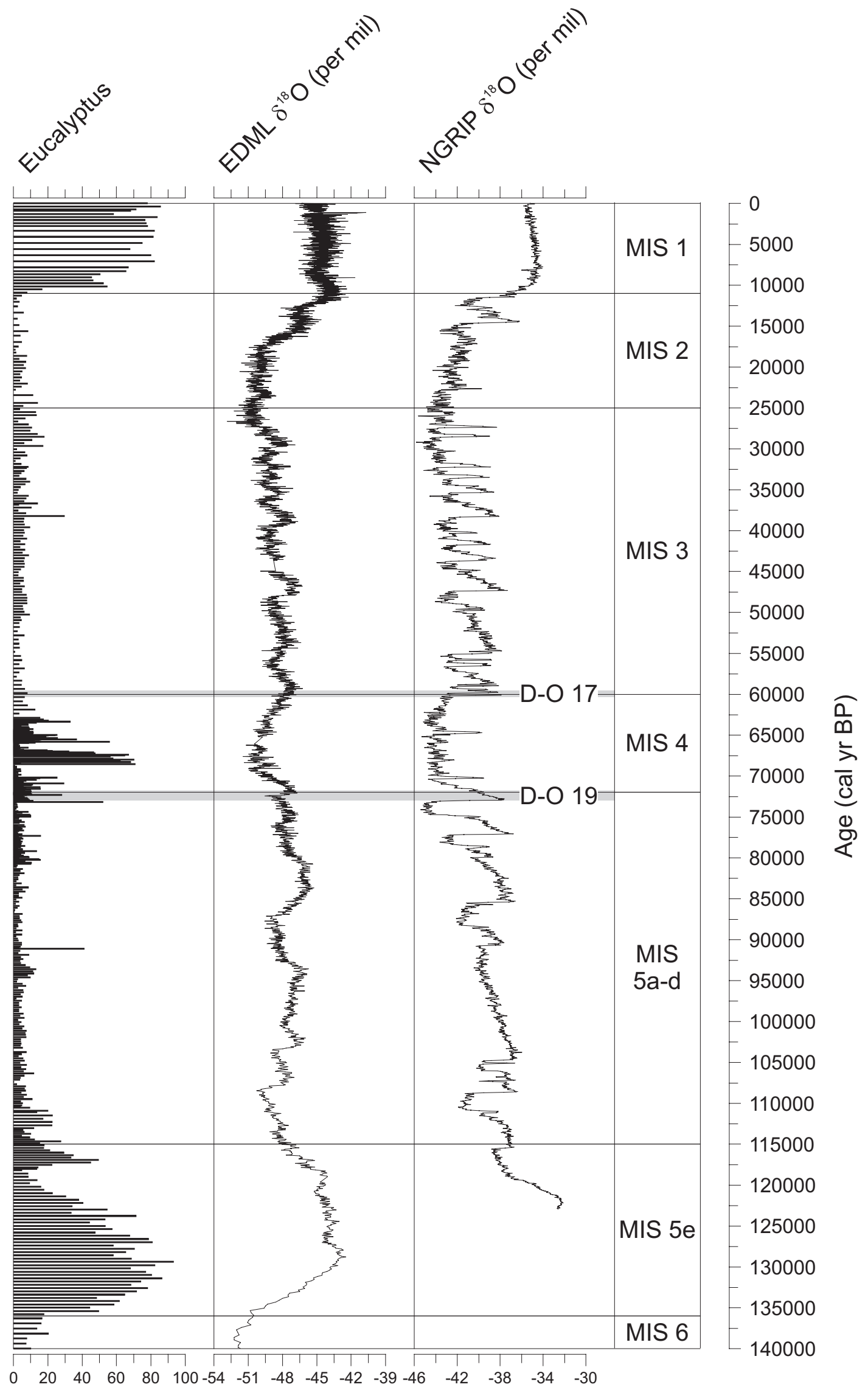

Figure 8. Comparison of the Eucalyptus record from Caledonia Fen with the oxygen isotope records from ice cores showing millennial scale variability during the last glacial period; the EDML (EPICA) core displaying Antarctic warm reversals and the NGrip Greenland core showing Dansgaard-0eschger (D-0) warm events (EPICA Community Members 2006). D-0 events 17 and 19 are marked 
are sufficiently long and refined to capture them, but their signals are relatively weak and inconsistent between records. Sea-surface temperature variations from marine records in the Southern Ocean have been related to Antarctic warm events (Barrows et al. 2007), while those from IMAGES Core MD01-2378, off northwestern Australia, show close affinity with Northern Hemisphere propagated D-O warm events (Dürkop et al. 2008). At Lynch's Crater, in northeast Queensland, Turney et al. (2004) recorded variations of a similar frequency and phasing to D-O events within the organic components of the sediments; these were suggested to have been the result of ENSO oscillations, whose signals were atmospherically transmitted to the North Atlantic, triggering the ice meltings that gave rise to the D-O cycles. However, variations were related to rainfall rather than temperature, had insufficient impact to notably alter adjacent dryland pollen assemblages, and the record only extends back to about 50,000 years ago.

In terms of duration and pattern, the interstadial does resemble a well-developed D-O cycle, rather than an Antarctic warm event (Figure 8), with an apparent sharp increase in temperature from stadial levels and then a more gradual but oscillating reduction, regardless of whether the longer or shorter period is considered. However, the dating falls into a period, between about 60,000 and 70,000 yr BP, when no such major event has been recorded. As this corresponds largely with MIS 4, which experienced cold conditions, including within the southern Australasian region (Barrows et al. 2007), warm phases are not to be expected. If the dates are systematically too old, as could be suggested from a comparison with the Kershaw et al. (2007) chronology, a correspondence with D-O 17, centered on 59,000 years ago (at the beginning of MIS 3), could be possible, although, from pattern-matching, a fit with D-O 19 (on the MIS 5a-4 boundary), with an estimated age of about 72,000 yr BP, is much more likely (EPICA Community Members 2006). This event had a duration of about 2000 years, similar to that estimated for zone CFD, and has a following short, but D-O unrecognised, warm event that could be correlated with zone CTB. Although the age difference appears to be about 6000 years, this is well within OSL dating uncertainty for Caledonia Fen. An older age may be plausible also on the grounds that OSL ages are systematically younger than those of radiocarbon at this site (Kershaw et al. 2007).

\section{The status of other abrupt events}

One of the major problems with the acceptance of the Caledonia Fen interstadial as a D-O event is that it is singular. Certainly, there is a great deal of variation in the expression of D-O events at different sites and in different locations: for example, Core MD01-2378 records only four identifiable events out of the most recent 17, but apparent representation of only one is extreme. However, it has been mentioned that there were other events, marked by sharp peaks in Eucalyptus and generally minor aquatic pollen representation, that were considered as potential D-O candidates in the full record in Caledonia Fen by Kershaw et al. (2007), on the basis that their frequency appeared comparable. It was hoped that a more certain impression of their duration as well as frequency could be gained from this temporally precise study. Unfortunately, the analysed sequence is beyond the main period of expression of D-O events and few clear minor events could be determined. Those that do exist suggest that eucalypt peaks extended over no more than one sample and hardly qualify as interstadials. It could well be that most can be accounted for by occasional over-representation through vagaries of pollen transport or flowering, but, considering that the strong eucalypt pollen rise at the beginning of zone CFD occurred within one sample, probably representing fewer than 100 years, there is reason to believe that marked sub-centennial forest or woodland responses to short-lived climatic events can be identified in the palaeo-record. 


\section{Conclusions}

The analysis of a contiguously sampled section of a sediment core from Caledonia Fen, centred on the only marked interstadial within the last glacial period, has revealed details of vegetation and climate at a centennial scale. The interstadial is estimated to cover a maximum of about 3000 years. It shows an initial abrupt change from alpine steppe vegetation to montane forest, perhaps within a century, with temperatures and precipitation close to those achieved within the Holocene. This expansion lasted for little more than 1000 years before there was a less abrupt decline in forest and its replacement by a predominantly grassland vegetation, considered to indicate much drier, but still relatively warm, conditions. A short reversal to moister conditions is suggested by a predominantly wet scrub vegetation without a eucalypt canopy, before a return to alpine steppe.

The best age estimate for the interstadial, based on OSL dating, is 66,800- 65,500 yr BP, which falls within the globally cool period of MIS 4. However, from comparison with various identified major global events and taking into consideration the uncertainties associated with the OSL ages, the best match is with D-O 19 that spans the MIS 5-4 boundary around 73,500 yr BP. Acceptance of this correlation, though, is constrained by the lack of any mechanism that will allow a signal, generally considered to have emanated from the North Atlantic, to be so prominent, and by the absence of any other marked D-O interstadials. Other events are recognised in the sequence, but are considered too short and frequent to qualify as interstadials. Based on existing knowledge, any explanation of the cause of the interglacial has to be considered speculative. It is fortunate, though, that, unlike the superficial Holocene peats, this archive will remain in the landscape to await the tools and knowledge necessary for explanation in the future.

\section{Acknowledgements}

We thank Kara Rasmanis and Stuart Clift for assistance with drafting illustrations.

\section{References}

Barrows, T.T., S. Juggins, P. De Deckker, E. Calvo and C. Pelejero 2007. Long-term sea surface temperature and climate change in the Australian-New Zealand region. Paleoceanography 22:1-17.

Bureau of Meteorology 1989. Climate of Australia, Australian Government Publishing Service: Canberra.

Dansgaard, W., S. Johnsen, H.B. Clausen, D. Dahl-Jensen, N. Gundestrup, C.U. Hammer and H. Oeschger 1984. North Atlantic climatic oscillations revealed by deep Greenland ice cores. In J. E. Hansen, and T. Takahashi (eds) Climate Processes and Climate Sensitivity, pp288-298. Washington: American Geophysical Union.

D'Costa, D.M. and A.P. Kershaw 1997. An expanded recent pollen database from southeastern Australia and its potential for refinement of palaeoclimatic estimates. Australian Journal of Botany 45:583-605.

Dürkop, A., A. Holbourn, W. Kuhnt, R. Zuraida, N. Anderson and P.M. Grootes 2008. Centennial-scale climate variability in the Timor Sea during Marine Isotope Stage 3. Marine Micropalaeontology 66:208-221.

EPICA Community Members 2006. One-to-one coupling of glacial climate variability in Greenland and Antarctica. Nature 444:195-198. 
Farrell, T.P. and D.H. Ashton 1973. Ecological studies on the Bennison High Plains. Victorian Naturalist 90:286-298.

Hope, G.S. 1968. Pollen studies at Wilsons Promontory. M.Sc. Thesis, Australia: Melbourne University.

Houlder, D.J., M.F. Hutchinson, H.A. Nix and J.P. McMahon 1999. ANUCLIM User Guide, Version 5.0. Canberra: Centre for Resource and Environmental Studies, Australian National University.

Kershaw, A.P. 1998. Estimates of regional climatic variation within southeastern Australia since the Last Glacial Maximum from pollen data. Palaeoclimates - Data and Modelling 3:107-134.

Kershaw, A.P., D.M. D’Costa, J. McEwen Mason and B.E. Wagstaff 1991. Quaternary vegetation of mainland southeastern Australia. Quaternary Science Reviews 10:391-404.

Kershaw, A.P., G.M. McKenzie, N. Porch, R.G. Roberts, J. Brown, H. Heijnis, L.M. Orr, G. Jacobsen and P.R. Newall 2007. A high resolution record of vegetation and climate through the last glacial cycle from Caledonia Fen, south-eastern highlands of Australia. Journal of Quaternary Science 22:481-500.

Kershaw, A.P., W. Southern, J.M. Williams and L.J. Joyce 1983. The vegetation record from the southeastern highlands of mainland Australia 40,000-3000 B.P. In J.M.A. Chappell and A. Grindrod (eds) Proceedings, First CLIMANZ Conference, Howman's Gap, Victoria, February 1981, pp16, 37-8, 62, 80-1, 101. Canberra: Dept. of Biogeography and Geomorphology, Australian National University.

Macphail, M. and A.R.H. Martin 1991. 'Spineless' Asteraceae II. Palynological and Palaeobotanical Association of Australasia Newsletter 23:1-2.

Martin, A.R.H. 1999. Pollen analysis of Digger's Creek Bog, Kosciuszko National Park: vegetation history and tree-line change. Australian Journal of Botany 47:725-744.

McKenzie, G.M. 1997. The late Quaternary vegetation history of the south-central highlands of Victoria, Australia: sites above 900m. Australian Journal of Ecology 22:19-36.

Pettit, J.R., J. Jouzel, D. Raynaud, N.I. Barkov, J.-M. Barnola, I. Basile, J. Bender, J. Chappellaz, M. Davis, G. Delaygue, M. Delmotte, V.M. Kitlyakov, M. Legrand, V.Y. Lipenkov, C. Lorius, L. Pepin, C. Ritz, E. Saltzman and M. Stievenard 1999. Climate and atmospheric history of the past 420,000 years from the Vostok ice core, Antarctica. Nature 399:429-436.

Sanchez Goñi, M.F., A. Landais, W.J. Fletcher, F. Naughton, S. Desprat and J. Duprat 2008. Contrasting impacts of Dansgaard-Oeschger events over a western European latitudinal transect modulated by orbital parameters. Quaternary Science Reviews 27:1136-1151.

Sturman, A. and N. Tapper 2005. The Weather and Climate of Australia and New Zealand. Second Edition. Oxford: Oxford University Press.

Svensson, A., K.K. Andersen, B. Bigler, H.B. Clausen, D. Dahl-Jensen, S.M. Davies, S.J. Johnsen, R. Muscheler, S.O. Rasmussen, R. Röthlisberger, J. P. Steffensen and B. M. Vinther 2006. The Greenland Ice Core Chronology 2005, 15-42 ka. Part 2: comparison to other records. Quaternary Science Reviews 25:3258-3267.

Turney, C.S.M., A.P. Kershaw, S. Clemens, N. Branch, P.T. Moss and L.K. Fifield 2004. Millennial and orbital variations in El Niño/Southern Oscillation and high latitude climate in the last glacial period. Nature 428:306-310.

West, R.G. 1961. Interglacial and interstadial vegetation in England. Proceedings of the Linnean Society of London 172:81-89.

Williams, M., E. Cook, S. van der Kaars, J. Shulmeister, T. Barrows and A.P. Kershaw 2009. Glacial and deglacial climatic patterns in Australia and surrounding regions from 35000 to 10000 years ago reconstructed from terrestrial and near-shore proxy data. Quaternary Science Reviews. 